\title{
A cost-effective algae-based biosensor for water quality analysis: Development and testing in collaboration with peasant communities
}

Cecilia Prudkin-Silva ${ }^{\text {a,1 }}$, Esteban Lanzarotti a,b,1 Lucía Álvarez $^{\text {a,c,2,1 }}$, María Belén Vallerga a , Matías Factorovich a,c,f, Uriel N. Morzan a,c,f,3, Margarita Petrona Gómez ${ }^{\text {d }}$, Natalia Paula González ${ }^{\mathrm{d}}$, Yamila Micaela Acosta ${ }^{\mathrm{d}}$, Felicitas Carrizo $^{\mathrm{e}}$, Emilio Carrizo ${ }^{\mathrm{e}}$, Silvio Galeano ${ }^{\mathrm{e}}$, María Gabriela Lagorio ${ }^{\mathrm{c}, \mathrm{f}}$, Ángela Beatriz Juárez ${ }^{\mathrm{g}}$, Raúl Esteban Ithuralde ${ }^{\mathrm{a}, \mathrm{c}, \mathrm{h}, \mathrm{i}, \mathrm{j}, 1}$, Juan Manuel Romero ${ }^{\mathrm{a}, \mathrm{c}, \mathrm{f}, *, 1}$, Constanza María Urdampilleta a,k,1

${ }^{a}$ Universidad de Buenos Aires, Facultad de Ciencias Exactas y Naturales, Grupo CoSensores, Buenos Aires, Argentina

${ }^{\mathrm{b}}$ Universidad de Buenos Aires, Facultad de Ciencias Exactas y Naturales, Departamento de Computación, Buenos Aires, Argentina

${ }^{\mathrm{c}}$ Universidad de Buenos Aires, Facultad de Ciencias Exactas y Naturales, Departamento de Química Inorgánica, Analítica y Química Física, Buenos Aires, Argentina

dEscuela de Agroecología, MoCaSE-VC, Santiago del Estero, Argentina

e Secretaría de Salud, MoCaSE-VC, Santiago del Estero, Argentina

${ }^{\mathrm{f}}$ CONICET - Universidad de Buenos Aires, Instituto de Química Física de los Materiales, Medio Ambiente y Energía (INQUIMAE), Buenos Aires, Argentina

${ }^{g}$ Universidad de Buenos Aires, Facultad de Ciencias Exactas y Naturales, Departamento de Biodiversidad y Biología Experimental, CONICET-Universidad de Buenos Aires, Instituto de Biodiversidad y Biología Experimental y Aplicada (IBBEA), Int. Guiraldes 2160, C1428EHA, CABA, Argentina

${ }^{\mathrm{h}}$ Universidad Nacional de Santiago del Estero (UNSE), Facultad de Agronomía y Agroindustrias, Departamento de Química, Santiago del Estero, Argentina

${ }^{i}$ UNSE/CONICET, Facultad de Humanidades y Ciencias Sociales y de la Salud, Instituto de Estudios para el Desarrollo Social, Santiago del Estero, Argentina

${ }^{\mathrm{j}}$ Universidad de Buenos Aires, Facultad de Ciencias Exactas y Naturales, Departamento de Química Biológica, Buenos Aires, Argentina

${ }^{\mathrm{k}}$ Instituto de Silvicultura y Medio Ambiente, Facultad de Ciencias Forestales, Universidad Nacional de Santiago del Estero, Santiago del Estero, Argentina

\section{A R T I C L E I N F O}

\section{Article history:}

Received 25 October 2020

Received in revised form 25 February 2021

Accepted 2 March 2021

Available online 13 March 2021

\section{Keywords:}

Pesticide detection

Rural communities

Absorbance

\begin{abstract}
A B S T R A C T
New anthropic potentially harmful compounds are released into the environment everyday. In this context, broad range bioassays have emerged providing economically viable and widely applicable alternatives due to their ability to detect the cumulative toxicity of mixtures of both known and unknown chemicals in a sample, thus allowing direct information about water quality.

Here we present a low-cost, wide-range algae-based biosensor that is easy to assemble and operate by untrained users and provides direct readings. It was developed as a request of a peasant social movement organization to assess the toxicity of drinking water in rural communities affected by pesticide spraying.
\end{abstract}

\footnotetext{
* Corresponding author at: Universidad de Buenos Aires, Facultad de Ciencias Exactas y Naturales, Grupo CoSensores, Buenos Aires, Argentina. E-mail addresses: juanm.romero18@gmail.com, jromero@qi.fcen.uba.ar (J.M. Romero).

1 These authors have contributed equally to this work.

2 Current address: Structural and Computational Biology Unit, EMBL Heidelberg, Meyerhofstraße 1, 69117 Heidelberg, Germany.

3 Current address: The Abdus Salam International Centre for Theoretical Physics, Strada Costiera 11, 34151 Trieste, Italy.
} 
Alginate matrix

Fluorescence

Naked-eye detection
Two fresh water algae strains, Scenedesmus acutus and Pseudokirchneriella subcapitata, were immobilized in alginate beads and tested as bioindicators. After incubation with different pollutants for five days, naked eye analysis by several observers proved to be a successful method to survey algae's growth and establish the detection limits. Best detection limits were $10 \mathrm{ppm}$ for technical-grade acid glyphosate, $15 \mathrm{ppm}$ for glyphosate-based formulation, $50 \mathrm{ppb}$ for atrazine formulation, $7.5 \mathrm{ppm}$ for copper and $250 \mathrm{ppb}$ for chromium. Absorbance measurements upon algae resuspension validated these results. The developed device was successfully tested in participatory workshops conducted at rural communities. Children, adults and elders with no scientific training were able to build the sensor and interpret the results, thus evaluating the quality of rain and well water used in their communities.

(C) 2021 Elsevier B.V. All rights reserved.

\section{Introduction}

Diverse chemical compounds are constantly released into the environment in the form of industrial and agricultural wastes (Saleh et al., 2020). Many of those are toxic for humans, hence their persistence in the environment imposes a risk on human health. Physicochemical analyses are not enough to assess the safety of different environmental matrices, as they analyze the presence of only a few sets of pollutants and usually need to be conducted in laboratories (Riedel, 1994).

In order to achieve an adequate, broad and frequent evaluation of water quality, it is necessary to implement different monitoring methods (Mankiewicz-Boczek et al., 2008). It is also convenient for these methods to be transportable and easy to perform by untrained people, so as to set up early warning systems. In this context, biosensors emerge as an efficient, easy-to-use, affordable and quick alternative even to sophisticated dispositives that perform several physicochemical analyses simultaneously (Marty et al., 1995).

Any useful biosensor should produce a detectable signal. There are several types of biological biosensors: (a) enzymatic, (b) whole cell-biosensors based on (i) immobilization of microorganism and subsequent amperometric, potentiometric, electrophotometric or colorimetric measurements, (ii) photosynthetic based, surveying $\mathrm{O}_{2}$ production, PSII fluorescence, etc or (iii) immunosensors (Sassolas et al., 2012).

Whole-cell biosensors have proven to be a powerful strategy to assess bioavailability of pollutants in environmental matrices (Zhang et al., 2019). Genetic engineering can be used so as to make organisms sensitive to specific pollutants. Genes from organisms naturally respondent to these pollutants can be transferred to systems that are easier to manipulate (Chaufan et al., 2014; Vera et al., 2014). In this way, fluorescence, bioluminescence or electrochemical signals can be generated upon contact of the cells with the pollutants (Ben-Yoav et al., 2011; Roggo and van der Meer, 2017; Zhang et al., 2017, 2019).

Another strategy for detecting the presence of pollutants is to measure specific damages to the reporter cells, such as genotoxic damage or photosynthetic impairment, using wild type organisms, thus diminishing the environmental risk of releasing them to the environment (Frense et al., 1998; Campanella et al., 2000). Microalgae are commonly used in environmental toxicology because they replicate fast and are easy to culture, without the need of being handled with extreme care. They are often used as early warning and/or broad spectrum sensors (Huzlik et al., 2017; Antonacci and Scognamiglio, 2020). However, in the last years many studies have shown that different microalgae species present a broad range of inhibition limits against different pollutants, which makes them possible specific sensors (Kashem et al., 2019; Han et al., 2019).

One approach to assess photosynthetic impairment is by electrochemical or fluorescent measurements of the whole cells (Campanella et al., 2000; Peña Vázquez et al., 2009; Védrine et al., 2003; Masojídek et al., 2011). Fluorescence-based approaches enable recovery of information about the state of the photosynthetic systems. In particular, they measure the return from excited to ground states in chlorophyll molecules which is directly correlated with cellular photosynthetic activities (Lagorio, 2011). This is of special interest when identifying different kinds of herbicides depending on their inhibiting characteristics over plant growth (Iriel et al., 2014).

Another approach is to assess the reproductive capacity of the cells, which paves the way to broad toxicity testing (Moreira dos Santos et al., 2002; Moreira-Santos et al., 2004). In the latter case, a strategy to produce transportable devices is to encapsulate cells in a matrix, which is one of the major steps for their construction (Gosset et al., 2019). Macroporous structure of calcium alginate has been tested for these purposes and it does not reduce the toxic effects of the pollutants under study (Abdel-Hamid, 1996). However these strategies usually require high-cost equipment, laboratory spaces and trained users, all of which makes it difficult for populations to get access to these methodologies. Moreover, preparative and assembling procedures require extreme conditions that may stress or sometimes damage the sensor cells.

One of the industrial activities which strongly contributes to environmental pollution is agriculture. In Argentina, the cultivated area has increased dramatically in the last decades, by means of the GMO crops, no-till farming and fertilizer/pesticide application (Cáceres and Gras, 2020). Despite the existence of regulations over these procedures, 
fumigation with potentially toxic chemicals is probably above the recommended limits (Mas et al., 2020). Glyphosate, atrazine and 2,4-D are some of the most employed compounds, which entail serious risk to human health because of their high persistence in surface and ground waters (Lupi et al., 2019; Alonso et al., 2018). Furthermore, it has also been proposed that surfactants and adjuvants added to the pesticide formulation pose a similar or even higher threat to human health than the active ingredients (Coalova et al., 2014). As these components are variable and not informed by the developing companies, it is very difficult to survey their presence in the environment by analytical techniques (Giesy et al., 2000).

The instrument we present here was developed as part of a joint project with the Peasant organization of Santiago del Estero (MoCaSE), Argentina, where rural communities are being affected by agriculture fumigation with different toxic compounds. This causes not only human health problems but also cattle death and crops spoilage, especially within those of the cucurbitaceae family. Pollutants spread on the field lixiviate and eventually contaminate underground waters, thus compromising its use as potable supplies. Noteworthily, drops deposited on roofs are then dragged by rainfall, which is stored for human consumption. As it was initially referred by members of MoCaSE, it was important that the developed device allowed broad water testing, with an affordable cost, easy assembling and providing simple results interpretable by non-trained users. At all stages of the biosensor development MoCaSE members were consulted about the different features of the assembling and testing process.

Taking these requirements into account, we developed an algae-based biosensor, using an immobilization strategy that does not resort to extreme synthetic conditions and allows results assessment by naked-eye observation. With this strategy, we analyzed the performance of Pseudokirchneriella subcapitata and Scenedesmus acutus against increasing concentrations of glyphosate (both technical-grade and commercial formulation), atrazine, copper and chromium. We also analyzed the results by means of absorbance and fluorescence measurements. In the last stages of this project, our device was successfully used by peasants in their rural communities, distant to any urban populations. We showed that in the conditions reported here, this strategy sustains physiologically relevant detection limits for a wide range toxicity water biosensor.

\section{Materials and methods}

\subsection{Calibration curves}

Technical-grade glyphosate, copper sulfate and sodium dicromate were purchased from Sigma-Aldrich. Glyphosatebased formulation was purchased from Gleba ${ }^{\circledR}$ (Glifoglex) and Atrazine formulation from Syngenta ${ }^{\circledR}$ (Gesaprim 90). Stock solutions and serial dilutions were prepared on the day of the assay in Milli-Q water. All other reagents were analytical grade.

\subsection{Algae growth and counting}

Scenedesmus acutus and Pseudokirchneriella subcapitata strains are currently kept in the Culture Collection of the laboratory of Protists Biology (Departamento de Biodiversidad y Biología Experimental) belonging to the Centro de Recursos Genéticos of Facultad de Ciencias Exactas y Naturales, Universidad de Buenos Aires. The standard CCAP 278/4 P. subcapitata strain was obtained from the Culture Collection of Algae and Protozoa, UK, and the BAFC CA 13 S. acutus strain was originally isolated from a highly polluted river in Buenos Aires, Argentina (Magdaleno et al., 2014). The cultures were maintained in $500 \mathrm{~mL}$ flasks containing $300 \mathrm{~mL}$ of enriched BBM medium (Bold's Basal Medium, (Bischoff and Bold, 1963). They were kept on an orbital shaker $(145 \mathrm{rpm})$ at $23 \pm 1{ }^{\circ} \mathrm{C}$, with continuous cool-white fluorescent light illumination $\left(80 \mu \mathrm{mol}\right.$ photons $\left.\mathrm{m}^{-2} \mathrm{~s}^{-1}\right)$. After 14 days, the inocula were ready to be used.

Algae concentration was determined using a Neubauer counting chamber and then several dilutions were prepared, in order to build calibration curves for both strains. Optic dispersion (OD) spectra of the suspensions were recorded on an Ocean Optics bench spectrometer, between 400 and $1000 \mathrm{~nm}$ (Fig. 1). Linear relationship between OD and algae concentration was then calculated by plotting OD at $680 \mathrm{~nm}$ vs. algae concentration and least squares linear fitting $\left(\mathrm{R}^{2}>\right.$ 0.99, Supp. Fig. 1). In order to determine the concentration of other suspensions in following experiments, these calibration curves were used.

\subsection{Immobilization and encapsulation}

The immobilization method used in this work was based on the one described in Moreira dos Santos et al. (2002). A $2 \%(\mathrm{w} / \mathrm{v})$ sodium alginate solution was prepared with warm sterilized BBM (approximately $50{ }^{\circ} \mathrm{C}$ ) and cooled at room temperature. An aliquot of an exponentially growing algal culture of $2 \times 10^{6}$ cells $/ \mathrm{ml}$ was thoroughly mixed, by gentle stirring, with equal volume of alginate solution to obtain an alginate-cell suspension of $1 \%$ alginate and $1 \times 10^{6}$ cells $/ \mathrm{ml}$. Beads were formed by dropping $375 \mu \mathrm{L}$ of the alginate-cell suspension over a $1 \mathrm{M} \mathrm{CaCl}_{2}$ solution, using a Pasteur pipette, from a height of approximately $10 \mathrm{~cm}$ and at a rate of approximately 1 drop per second. The beads were stirred in the $\mathrm{CaCl}_{2}$ solution for $30 \mathrm{~min}$ and then washed with distilled water (Fig. 2B).

For the device assembly, eight immobilized algae beads were placed in an Eppendorf ${ }^{\circledR}$-like tube cap, as shown in Fig. 2C. The space between the beads was filled with BBM culture medium. Then, a semipermeable membrane was located covering the beads, and it was secured in place with the upper section of the tube. The entire process is depicted in Fig. 2A-C. 


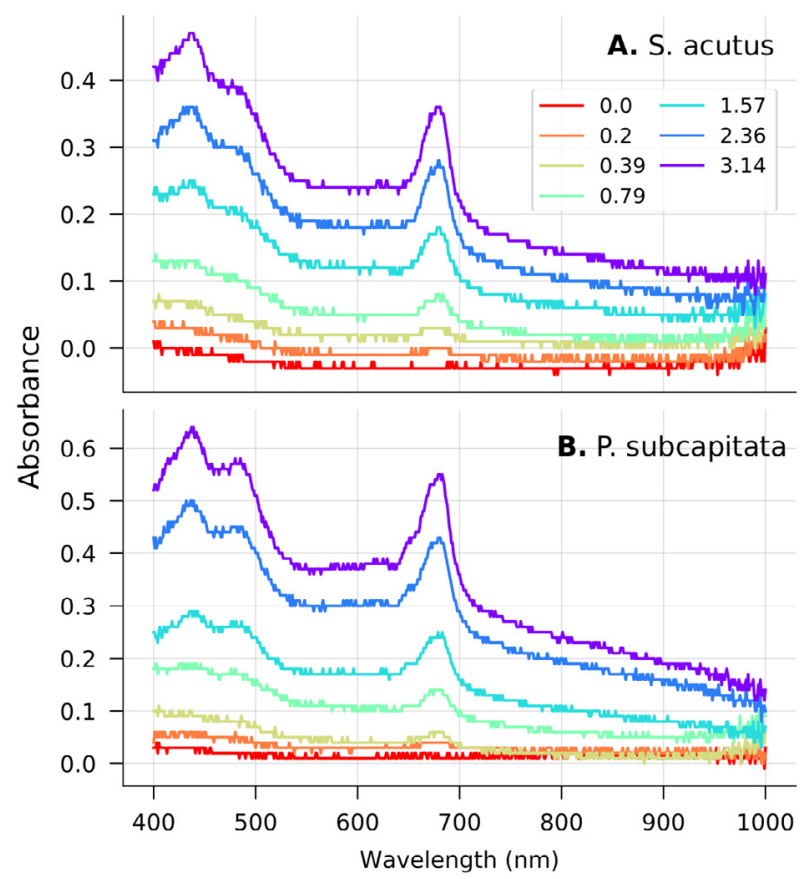

Fig. 1. OD spectrum of algae suspension for S. acutus (A) and P. subcapitata (B). Plot legend shows algae concentration in $10^{8} \mathrm{cel} / \mathrm{mL}$.

\subsection{Assay assembly}

The assembly consisted in setting three devices into a rack, which was then placed in a Falcon tube containing the appropriate pollutant solution. After placing, the Falcon was sealed and every device was checked in order to detect and discard air bubbles and ensure total immersion. The Falcon tubes were positioned on cardboard holders, each holder containing 16 tubes. Each calibration curve consisted in 8-10 points with one Falcon tube per point, and was conducted by duplicate. A plastic basin was put on top of each holder, with a LED bulb (Phillips, $12 \mathrm{~W}, 6500 \mathrm{~K}$ ) at its center to provide a stable light source for the algae (Fig. 2D).

\subsection{Fluorescence measurements}

Variable chlorophyll fluorescence was recorded by means of a pulse amplitude modulated fluorometer, Hansatech FMS-1, at room temperature (Ritchie and Bunthawin, 2010; Mouget and Tremblin, 2002). Measuring beam was an amber $(594 \mathrm{~nm})$ modulated light with $1.8 \mu \mathrm{s}$ pulses, with longer periods in between. In order to avoid inducing photosynthesis, this beam reaches a very low integrated flux $\left(\sim 0.05 \mu \mathrm{mol} \mathrm{m}^{-2} \mathrm{~s}^{-1}\right)$. Decoupling fluorescence from ambient and reflected light is assured by registering light in phase with the modulated beam.

Devices containing algae beads were taken off its rack and placed in the Hansatech clips - originally designed for measuring leaves. Sample adaptation to darkness was assured for over 20 min before starting measuring protocols. Maximum quantum yield of PSII was determined as the quotient between variable and maximum fluorescence $\left(F_{\mathrm{v}} / F_{\mathrm{m}}\right)$ when applying a saturating pulse (Genty et al., 1989; Maxwell and Johnson, 2000). Actinic light intensity was then gradually increased. Each different light intensity was maintained for a $250 \mathrm{~s}$ period, therefore allowing algae to reach steady state fluorescence. Photosystem II yield $\left(\Phi_{\mathrm{PSII}}\right)$ at each actinic light was measured by applying a saturating pulse once steady state was achieved and calculated according to:

$$
\Phi_{P S I I}(A L)=\frac{F_{m}^{\prime}-F_{T}}{F_{m}^{\prime}}
$$

where $F_{m}^{\prime}$ and $F_{T}$ stand for the maximum and steady state fluorescence, respectively. Actinic light intensities were 0,33 , $130,325,630$ and $1085 \mu \mathrm{mol} \mathrm{m}^{-2} \mathrm{~s}^{-1}$.

\subsection{Naked eye observations}

After 5 days, devices in control treatments showed high algae concentration (Fig. 2E). Naked eye detection limit (DL) was put on different observants' consideration and 8 independent replies were received. From different ways of working 
out the collective decision, for simplicity and reliability, it was selected the alternative that had received the most votes (Saaty, 1990). The accumulation of votes corresponding to lower concentrations over total votes (\%av ${ }_{n}$ ) was calculated to evaluate cases in which opinions were scattered between two concentrations (Supp. Table 1).

$$
\% a v_{n}=\sum_{k=1}^{n} \frac{V_{k}}{V} \cdot 100
$$

where $n$ stands for the tube order in crescent pollutant concentration, $v_{n}$ stands for the votes amount for the $n$ tube and $V$ stands for the total votes. Results were analyzed and photographed using an UV-Vis Transilluminator (see Fig. 3).

Prior to absorbance measurements, the beads from each tube cap were carefully extracted and relocated into plastic tubes containing $200 \mu \mathrm{l}$ of $0.25 \mathrm{M}$ Sodium Citrate solution, to propitiate the disassembly of the beads. After 20 min of incubation, the remaining beads were completely dissolved using a vortex mixer for approximately $30 \mathrm{~s}$. The resuspended samples were used shortly after resuspension.

\subsection{In situ assay}

Joint work between CoSensores group and MoCaSE peasant organization started in 2014 with a broad environmental survey and careful analysis of pollution dynamics (Lanzarotti et al., 2016). After the design and optimization of the monitoring device, a participatory water quality survey was agreed with the peasant communities in Quimili department, Santiago del Estero, Argentina. The survey was staged as a two-day in situ bioassay workshop, and it was conducted and coordinated by group members in 4 communities, in late September 2017.

In the first stage of the workshop, peasants from nearby communities gathered and brought water samples to be analyzed. Samples were collected from wells and rainfall storages used from everyday human consumption. Algae beads and measuring devices were assembled and a 10 tube calibration curve was set (as described in Section 2.4). After 5 day incubation, results were discussed in the second stage of the workshop, in which green color intensity in the devices was observed and evaluated by all the workshop participants in order to build the calibration curve and evaluate water samples quality.

\subsection{Considerations about cost and implementations}

A typical field assay like the one described above demands a budget of approximately 33 USD in chemicals plus nonreusable plastic material, and 80 USD in equipment and electricity, as seen in Supp. Table 1. Each assay holds a 10 point calibration curve and a maximum of 27 samples (by duplicate). Therefore, each sample demands 1.23 USD in chemicals and non-reusable material. In the field assay conducted in this work, MoCaSE organization spent 211 USD, approximately 2 USD per each water source analyzed.

\section{Results and discussion}

\subsection{Naked eye observation}

The assay's design enables naked eye visualization of algae beads' response to the chemical standard and glyphosatebased formulation (Fig. 3). Naked eye observation of green shade and intensity through the device is related to algae growth and reproduction. At pollutants' higher concentrations the device appears transparent because the algae does not grow, while in the absence of pollutant the device looks greener because of the intense algae growth. The two strains of algae showed sensitivity to all the contaminants to which they were exposed. The direct observation of the successive concentrations of pollutants with respect to the control shows a gradual decrease in green (except for the formulated glyphosate lowest concentration). Trends are clear although the differences between correlative tubes is not always easy to visualize. Having an integral view of all samples set is important for the algae response interpretation.

Naked eye DL was consensual by votes'accumulation percentages superior to $75 \%$ for all the curves (Supp. Table 1). Naked eye DL were superior for P. subcapitata than for S. acutus (Table 1) for glyphosate and atrazine, meaning that $S$. acutus bioassay shows more sensitivity for them. S. acutus Naked eye DL was $10 \mathrm{ppm}$ for technical-grade glyphosate, 15 ppm for glyphosate-based formulation, $0.05 \mathrm{ppm}$ for Atrazine, and $7.5 \mathrm{ppm}$ for Copper; while P. subcapitata Naked eye DL was $15 \mathrm{ppm}$ for Standar Glyphosate, $20 \mathrm{ppm}$ for glyphosate-based formulation, $0.125 \mathrm{ppm}$ for Atrazine, and $0.25 \mathrm{ppm}$ for Chromium.

When compared to other whole-cell, easy-to-read biosensors (Supp. Table 2), the device presented here shows reasonable detection limits. Although our $10 \mathrm{ppm}$ DL for glyphosate is a little higher than the $1.1 \mathrm{ppm}$ DL registered by Abdel-Hamid (1996) or the $3.6 \mathrm{ppm}$ DL by Shao et al. (2002), it is still in the same range. Regarding atrazine, we were able to detect $50 \mathrm{ppb}$, slightly above the $10 \mathrm{ppb}$ detected by Gosset et al. (2019), by using fluorescence analysis, but below the $220 \mathrm{ppb}$ determined by Abdel-Hamid (1996). Detection limits for metals can be found in a study conducted by Corbisier et al. (1999), who reported a $1.3 \mathrm{ppm}$ detection limit for copper and $520 \mathrm{ppb}$ for chromium. Therefore, our detection limits for metals ( $7.5 \mathrm{ppm}$ for copper and $250 \mathrm{ppb}$ for chromium) are also in the range found in previous studies. 


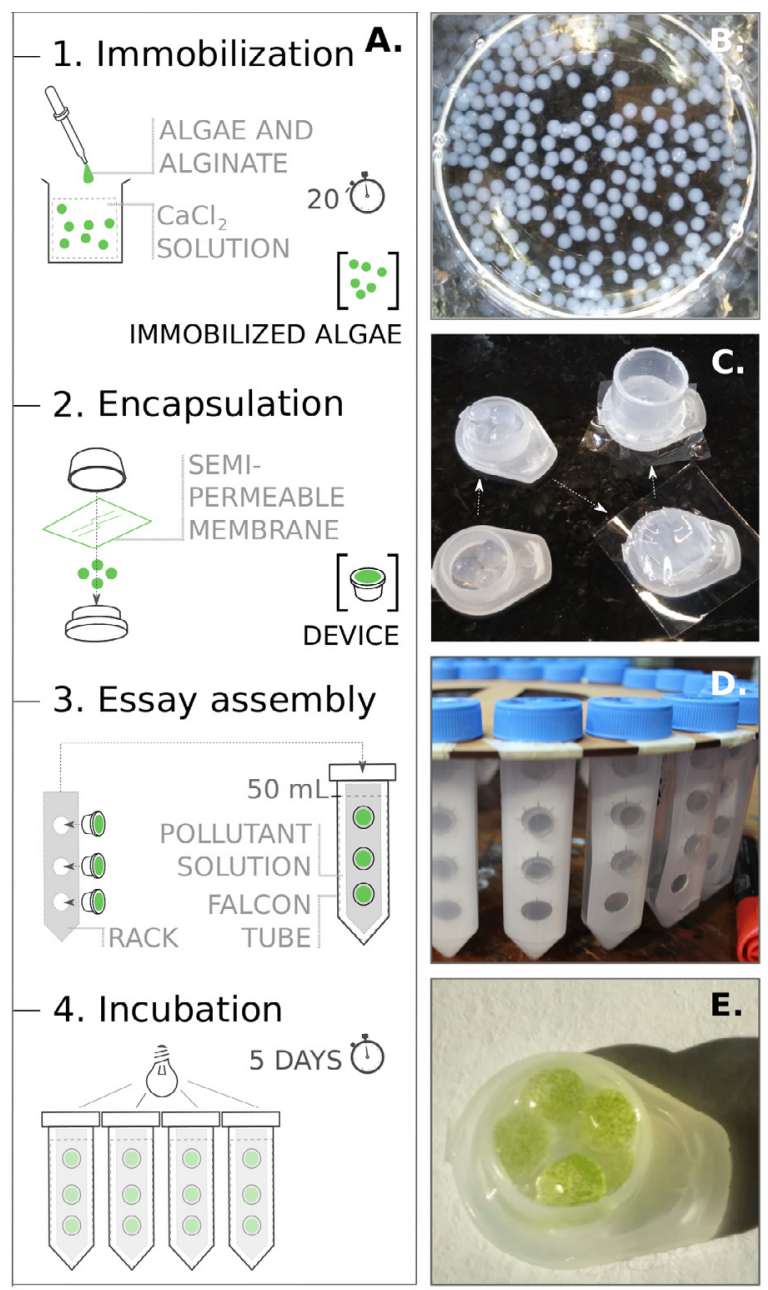

Fig. 2. Assay overview. A. Assay stages indicating main components. B. Alginate- $\mathrm{Ca}^{2+}$ beads containing initial algae concentration. C. Device assembly. D. Assay assembly. E. Device with grown algae after 5 days incubation. Scheme based on the design created by Cooperativa de Diseño (http://www.cooperativadedisenio.com/).

Table 1

Detection limit by different observation methods for both strains (P. subcapitata and S. acutus) and for several pollutants.

\begin{tabular}{llll}
\hline Strain & Pollutant & Naked eye DL $(\mathrm{ppm})$ & Absorbance DL $(\mathrm{ppm})$ \\
\hline \multirow{4}{*}{ S. acutus } & Acid glyphosate & 10 & 15 \\
& Glyphosate-based formulation & 15 & 40 \\
& Atrazine & 0.05 & 0.05 \\
& Copper & 7.5 & 7.5 \\
\hline \multirow{3}{*}{ P. subcapitata } & Acid glyphosate & 15 & 8 \\
& Glyphosate-based formulation & 20 & 10 \\
& Atrazine & 0.125 & 0.15 \\
& Chromium & 0.25 & 0.25 \\
\hline
\end{tabular}

\subsection{Absorbance measurements}

\subsubsection{Absorbance measurements on immobilized algae}

Before resuspending the algae beads with citrate solution, it was tested whether the absorbance spectrum could be acquired with no algae resuspension, that is, having the measuring beam going throughout the device. It was not conceived as a method of quantification at this time, but rather as a proof of concept for future work. To this end, a modified plastic cuvette was used as a device holder. Due to technical limitations, only some points of the acid glyphosate curve for S. acutus were measured on a bench spectrophotometer. The recorded spectra showed a typical Chl absorption spectra 

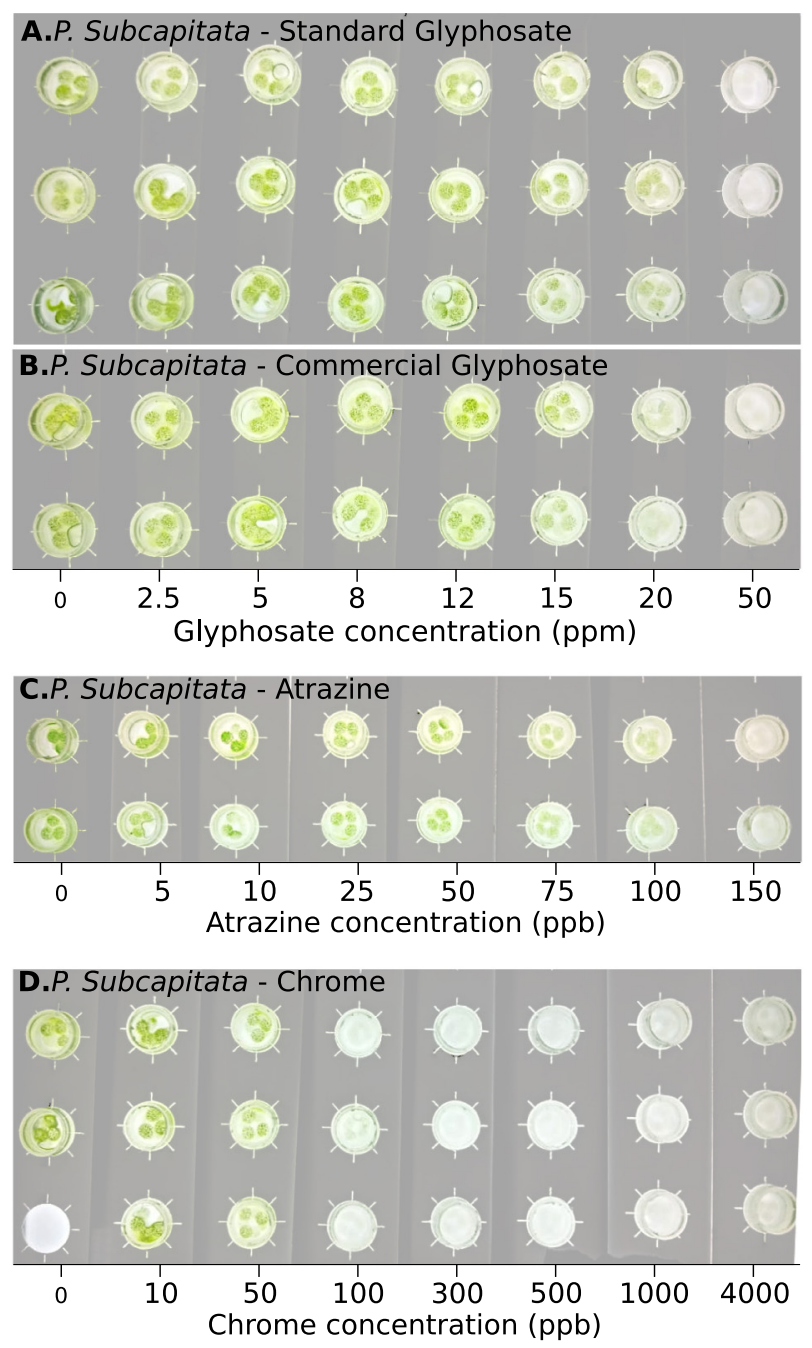

Fig. 3. Naked eye observation of $P$. subcapitata strain response to increasing (left to right) pollutant concentration. A. Technical-grade acid glyphosate. B. Glyphosate-based formulation. C. Atrazine. D. Chromium.

mounted on a dispersion line, resulting from alginate polymer and algae walls. However, after correction of the dispersion distortion, the absorption band of $680 \mathrm{~nm}$ was clearly recovered, as shown in Supp. Fig. 2.

At first, some growth induction can be observed at $5 \mathrm{ppm}$ glyphosate concentration. Then, the reduction of algae concentration is observed at $12 \mathrm{ppm}$ due to the strong decrease in the absorption band and null absorbance is registered at $20 \mathrm{ppm}$. These results are in agreement with those measured by absorbance upon resuspension, shown in the next section. This implies that measuring the absorbance throughout the device arises as a possible technique, sensitive to low pollutant concentrations.

\subsubsection{Absorbance measurements on resuspended algae}

Upon resuspension of the algae beads, absorbance at $465 \mathrm{~nm}$ was recorded after placing the samples in 96-well multiplates. Absorbance for the three devices in each curve point was averaged, each curve was normalized and the two curves for each pollutant were averaged computing the statistical error. Data for each point were compared to control by Welch's unequal variances t-test.

Fig. 4A and B show both S. acutus and P. subcapitata response to technical-grade glyphosate and glyphosate-based formulation. It is interesting to notice that both strains show a slight growth increase at low technical-grade glyphosate concentrations (2.5 ppm). This behavior is known as hormesis and is in agreement with previous studies on plants and algae (Cedergreen et al., 2007). On the other hand, glyphosate-based formulation shows no hormesis, which can be a result of the undeclared adjuvants in the formulation. Above $40 \mathrm{ppm}$ all growth is inhibited, reaching absorbance around 0.25 (probably resulting from sample's scattering). 


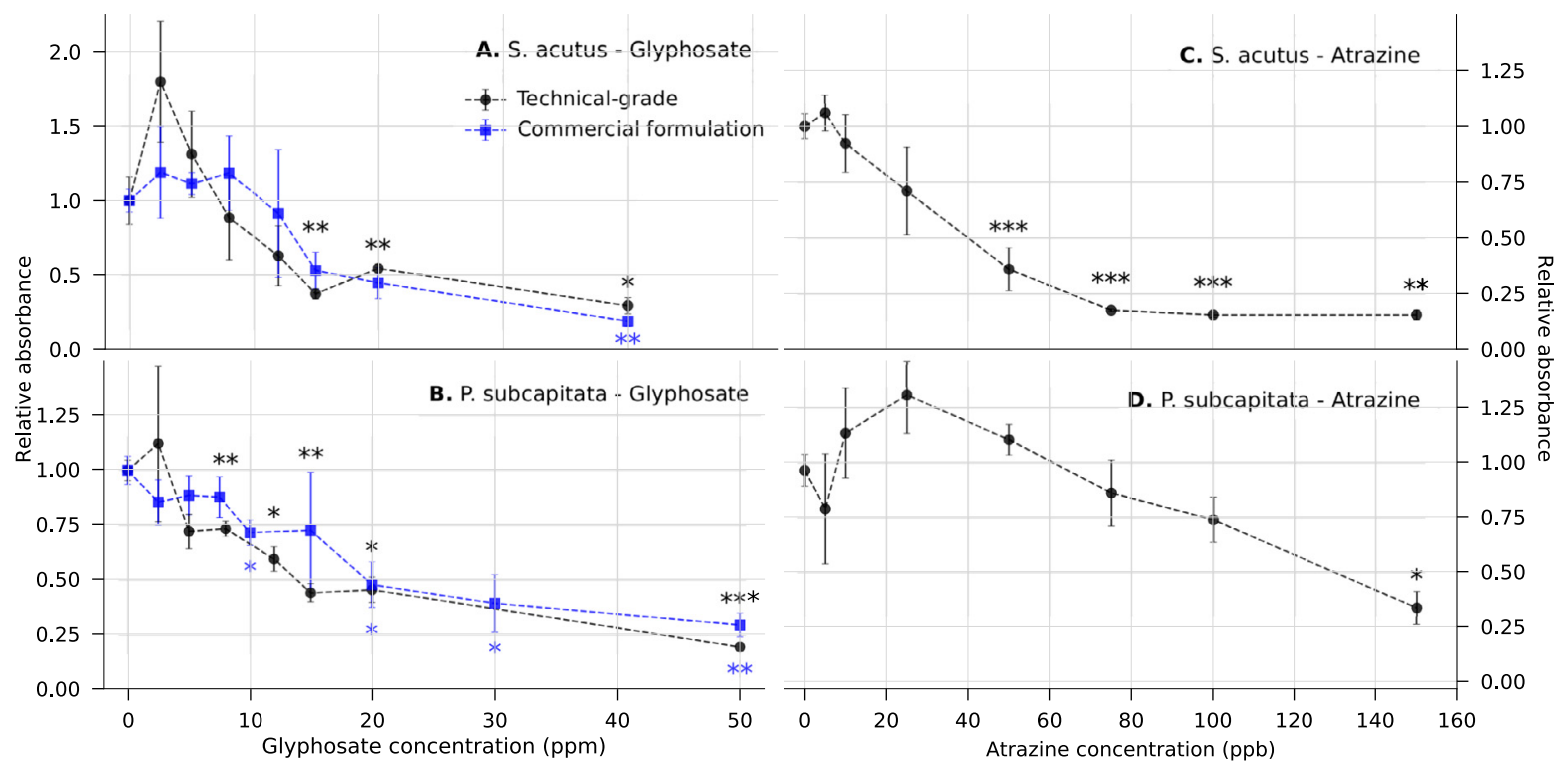

Fig. 4. Algae response to increasing pollutant concentration measured by absorbance at $465 \mathrm{~nm}$. A. S. acutus, glyphosate. B. P. subcapitata, glyphosate. C. S. acutus, atrazine. D. P. subcapitata, atrazine. Values normalized by control absorbance. Bars indicate mean standard error. Asterisks indicate statistical significance when compared to control (Welch's unequal variances t-test; $n=2 ;{ }^{*}, p<0,1 ;{ }^{* *}, p<0.05 ;{ }^{* * *}, p<0.01$ ). Notice asterisks follow legend color code in A and B.. (For interpretation of the references to color in this figure legend, the reader is referred to the web version of this article.)

The detection limits (Table 1) for S. acutus are $40 \mathrm{ppm}$ for glyphosate-based formulation and $15 \mathrm{ppm}$ for technical-grade glyphosate, while for $P$. subcapitata these values are reduced to $8 \mathrm{ppm}$ for acid glyphosate and $10 \mathrm{ppm}$ for the commercial formulation (Fig. 4A and B, respectively). Conversely, in the case of atrazine S. acutus provides a much lower detection limit than P. subcapitata (50 and $150 \mathrm{ppb}$ respectively), as seen in Fig. 4C and D, respectively. Moreover, certain levels of growth enhancement are observed at small atrazine concentrations, which, to our knowledge, have not been reported before.

As seen in Fig. 5, S. acutus was tested against copper, showing a typical sigmoidal curve with a 7.5 ppm detection limit. Last, $P$. subcapitata was tested against chromium showing a $0.25 \mathrm{ppm}$ detection limit.

\subsection{Variable fluorescence measurements}

A characteristic fluorescence time trace for algae grown under control conditions is shown in Fig. 6A. Although fluorescence photons emerging from algae photosystems go across cell walls, alginate polymer and device cover before reaching the detector, fluorescence signal was retrieved clearly. Even though fluorescence of immobilized algae has been measured previously, this is, to our knowledge, the first time variable fluorescence under increasing illumination is studied. Unlike stationary fluorescence, variable fluorescence analysis enables elucidation of potential damage or subtle structural chances upon contact with pollutant solution by revealing the physiological photosynthetic parameters.

Fig. $6 \mathrm{~B}$ displays the quantum yields of photophysical decay $\left(\Phi_{\mathrm{C}}\right)$, PSII quantum yield $\left(\Phi_{\mathrm{PSII}}\right)$ and non-photochemical quenching $\left(\Phi_{\mathrm{NPQ}}\right)$ as a function of actinic light. Interestingly, $\Phi_{\mathrm{PSII}}$ in darkness is well conserved with respect to the values under normal growth conditions $(\sim 0.8)$ (Falace et al., 2018). This indicates that algae grown in control conditions remain healthy and that immobilization and incubation techniques do not cause stress, which could distort assay results. Moreover, $\Phi_{\text {PSII }}$ has a decreasing exponential dependence with increasing irradiation intensity, which is the expected behavior (de Baat et al., 2018). As irradiance increases, energy is dissipated both through photophysical decay and non-photochemical quenching.

The behavior described above for control conditions is also observed for all other glyphosate concentrations (data not shown). An intermediate irradiance intensity $\left(325 \mu \mathrm{mol} \mathrm{m} \mathrm{m}^{-2} \mathrm{~s}^{-1}\right.$ ) was chosen to compare the physiological parameters along the glyphosate concentration curve. Supplementary Fig. 3 shows the parameters studied for both the active ingredient and the commercial formulation of glyphosate (panels A and B, respectively). Surprisingly, PSII yield does not decrease with increasing glyphosate concentration. This means that, despite blocking the synthesis of aromatic amino acids (Duke, 1988; Salman et al., 2016; Smedbol et al., 2018) photosynthetic machinery is not affected. In other words, glyphosate inhibits algae growth (as shown in the growth curve) but does not affect photosynthetic rate. 


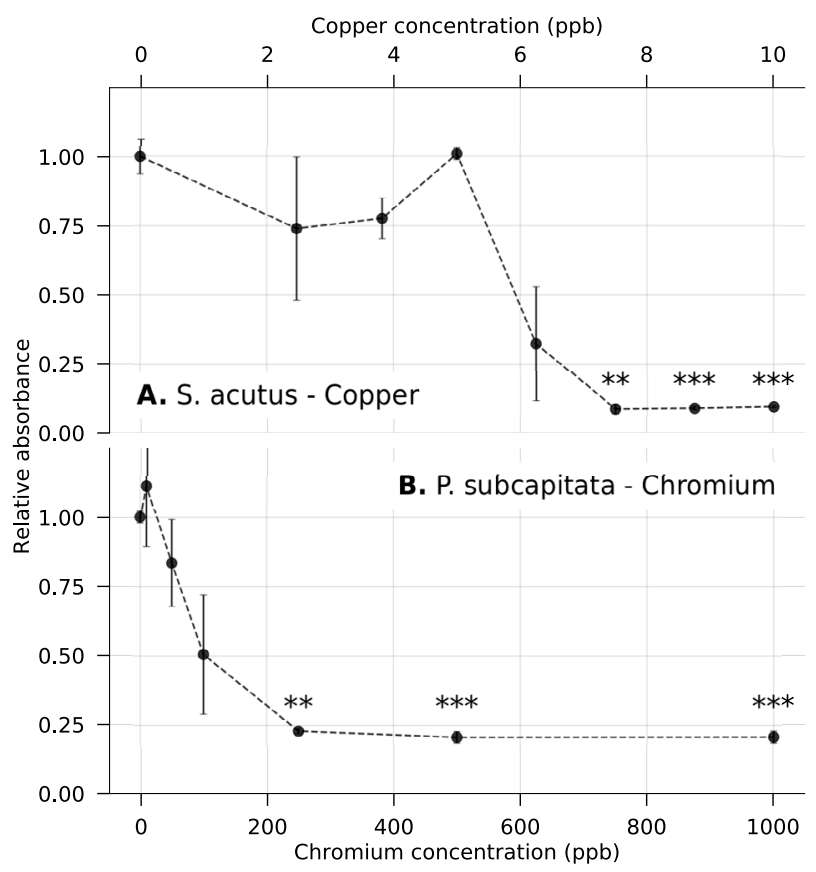

Fig. 5. Algae response to increasing concentration of common toxic compounds measured by absorbance at $465 \mathrm{~nm}$. Response of S. acutus to copper and P. subcapitata to chromium (A and B, respectively). Values normalized by control absorbance. Bars indicate mean standard error. Asterisks indicate statistical significance when compared to control (Welch's unequal variances t-test; $n=2 ;{ }^{*}, p<0,1 ;{ }^{* *}, p<0.05 ;{ }^{* * *}, p<0.01$ ).
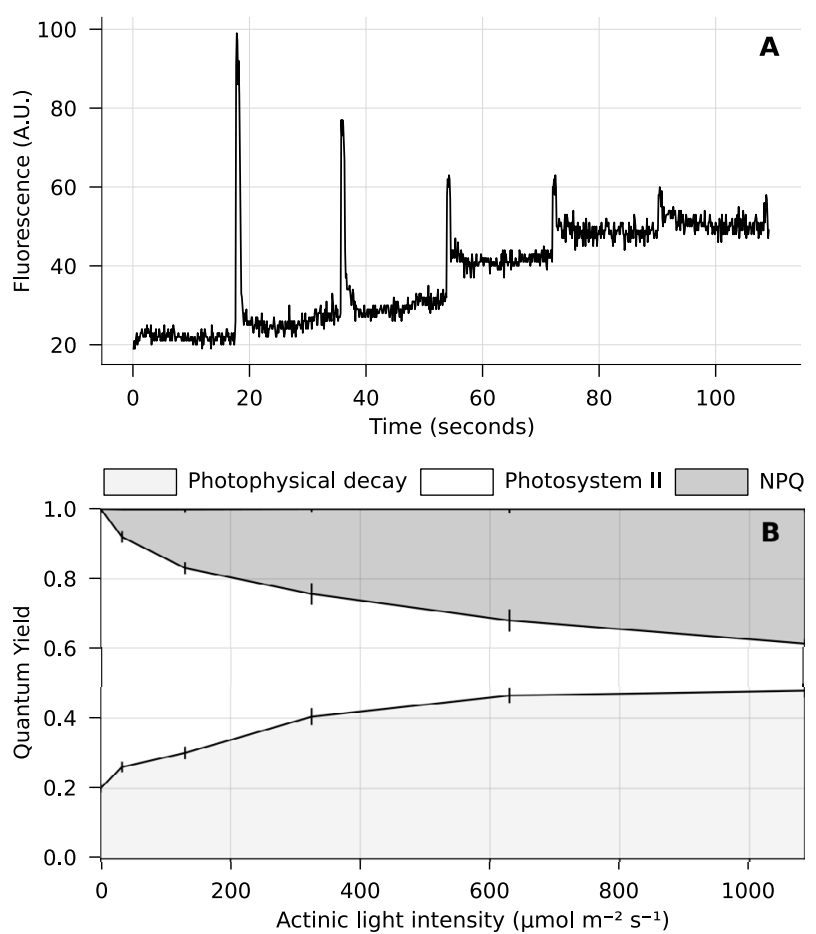

Fig. 6. Variable fluorescence experiment for P. subcapitata. A. Fluorescence as a function of time for control assay. B. Quantum yields as a function of actinic light intensity. Color reference over graph. Bars indicate mean standard error.. (For interpretation of the references to color in this figure legend, the reader is referred to the web version of this article.) 


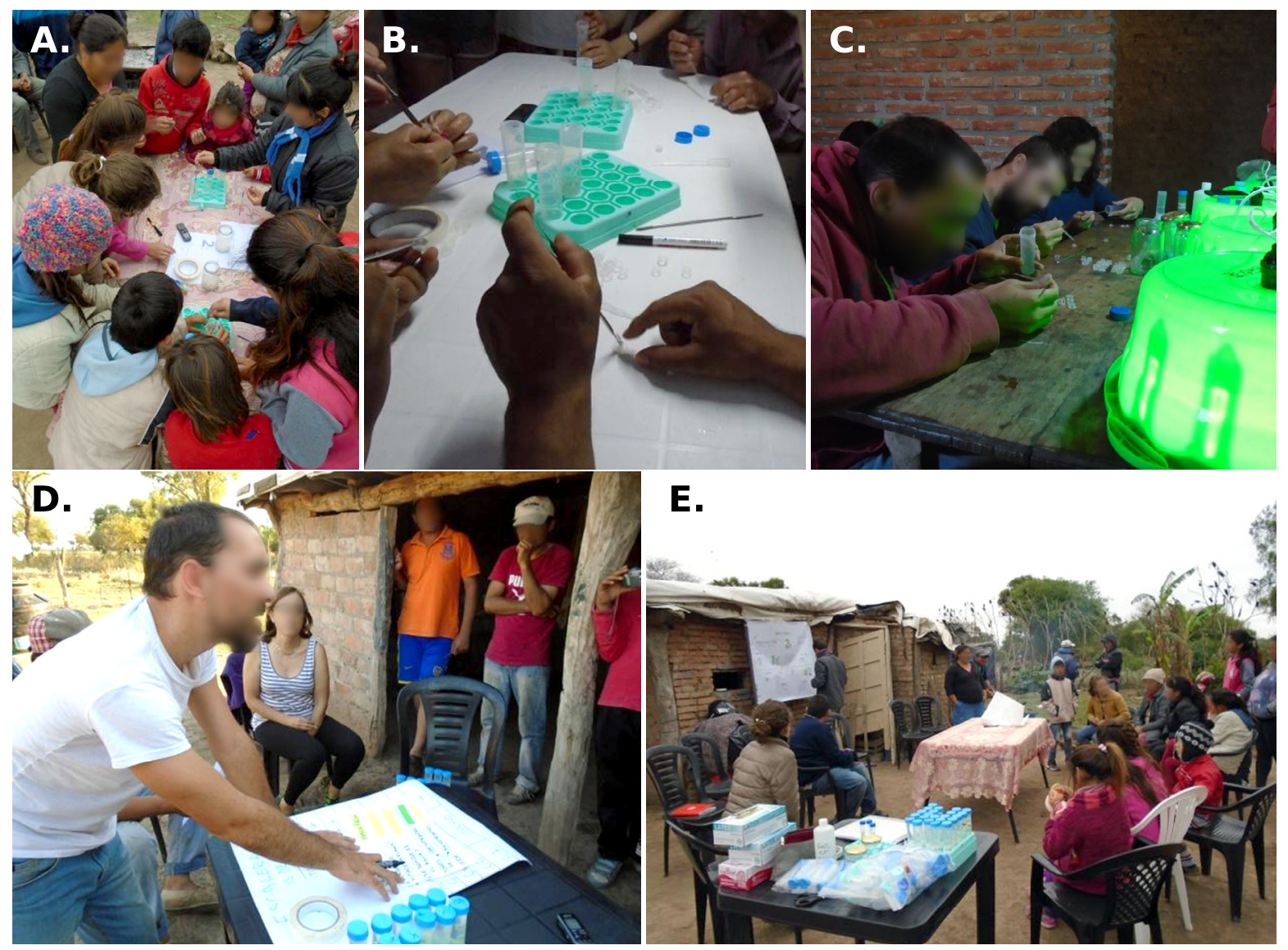

Fig. 7. Stages of biosensor workshop. Panels A, B, and C: biosensor assembly process. Panels D and E: Discussion of biosensor results.. (For interpretation of the references to color in this figure legend, the reader is referred to the web version of this article.)

\subsection{Field assay}

Participatory workshops were conducted in 4 peasant communities, evaluating a total of 25 water samples by duplicate. An average of approximately 12 people took part in each of the workshops, which lasted about $4 \mathrm{~h}$ for the assembly stage and about $2 \mathrm{~h}$ for results discussion. Fig. 7A-C displays different stages of the assembling process, showing the participation of children and adults with no scientific training. After 5 days of algae incubation, green color in the devices was quantified by naked eye observation, discussed among the participants and agreeing about a greening criterion, as shown in Fig. 7D-E.

Fig. 8A-B show some typical obtained calibration curves and the agreed greening for each tube (C). Given the chemical complexity of the drinking water matrix, sample results (examples in Fig. 8D) were carefully discussed, taking into account not only biosensor greening but also other parameters measured (such as temperature, $\mathrm{pH}$ or turbidity) and relevant information explained by peasants (distance to roads, pollution, winds, etc.).

\section{Conclusions and perspectives}

In this work we have presented a broad range biosensor for water quality analysis aimed to prevent consumption of agronomic pollutants spread in the environment. The developed sensor was based on green microalgae immobilized in an alginate matrix. The idea, optimization and testing of the biosensor was developed by a multidisciplinary consortium of senior and junior researchers (CoSensores) in coordination with an argentinian peasant organization, MoCaSE-VC. The assembly procedure is easy and does not pose any health risk, thus being feasible for non trained users to build it. Testing water quality with this technique costs less than 2 USD per-sample, making it a cost effective method for broad water surveys. Moreover, results are easily detectable with naked eye observation and hold very good sensibility for these kind of devices.

We have tested two different algae strains, S. acutus and P. subcapitata, finding the first one to be more sensitive to atrazine $(\mathrm{DL} \sim 50 \mathrm{ppb})$ and the second one more sensitive to glyphosate ( $\mathrm{DL} \sim 10 \mathrm{ppm}$ ). Thinking of future developments 

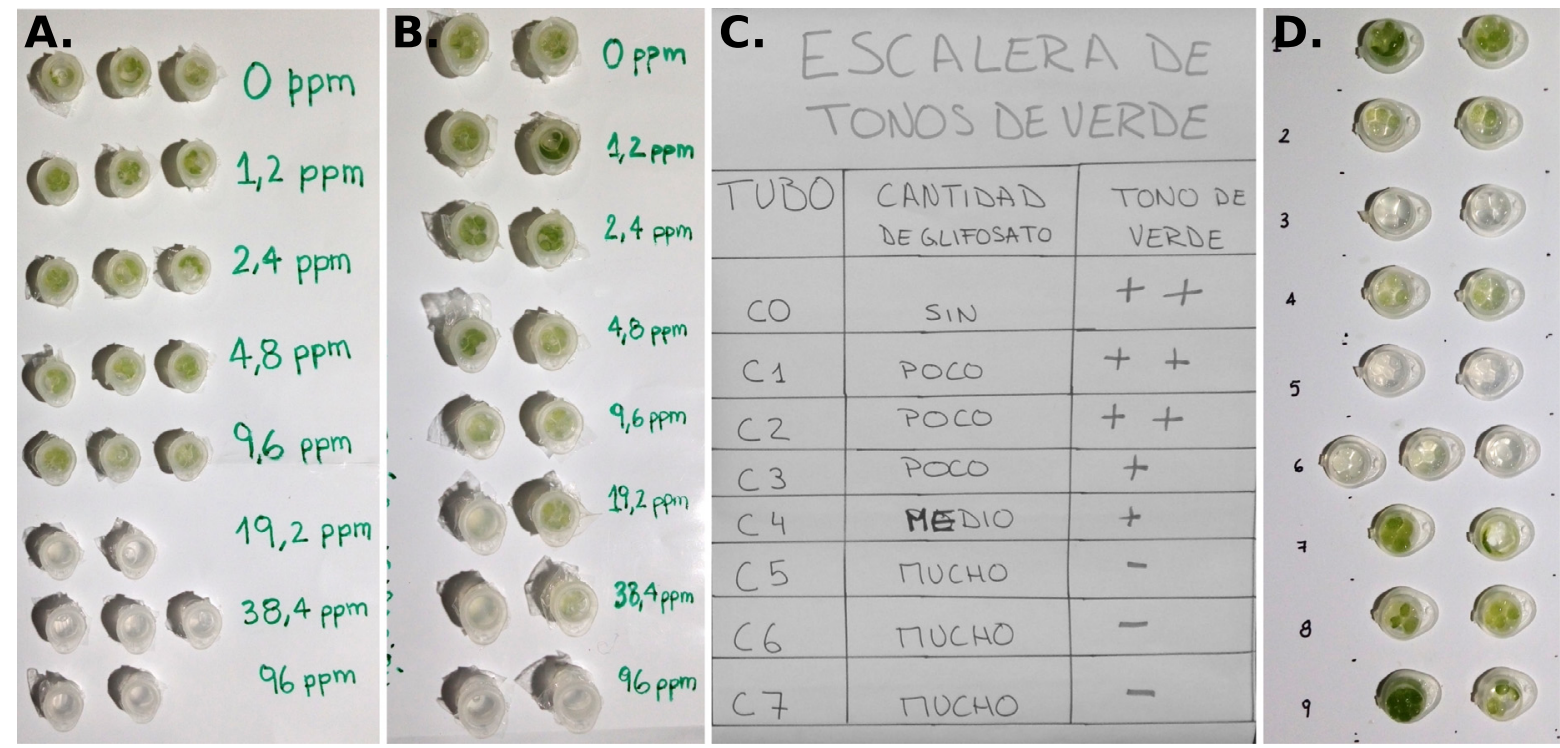

Fig. 8. Example results of typical field assay. A and B. Calibration curves from two different workshops. Numbers in figure indicate glyphosate concentration in ppm (notice comma is used as decimal separator). C. Discussion of glyphosate calibration curve. Sin: without, poco: low, medio: medium, mucho: high, tono de verde: greening. D: Example results of samples assessment.

employing this sensor, we performed both absorbance and fluorescence measurements on the device, for chosen glyphosate treatments. Absorbance at $680 \mathrm{~nm}$ proved to be, upon scattering correction, an interesting probe for algae concentration, making it a good candidate for result quantification in field assays. Variable fluorescence measurements also showed good signal and allowed retrieval of a full light curve response. Interestingly, algae photosynthetic efficiency shows no reduction upon glyphosate treatment, compatible with the fact that its action pathway does not affect photosystems.

The biosensor performance was tested in field assays by means of participatory workshops in peasant's communities, using local water supplies and reservoirs as samples. Algae immobilization and device assembly were successfully conducted by children, adults and elders with no previous scientific training. Technical-grade glyphosate calibration curves built by them also showed a detection limit between 10 and $20 \mathrm{ppm}$. Moreover, the use of the biosensor on the local samples also proved to be successful, showing an evident strong intensity of green color in those samples from clean water sources and a much weaker intensity in those coming from sources known to be polluted.

The reported biosensor represents a powerful, cost effective and simple tool which can be used by non trained operators to perform broad-range environmental surveys in rural contexts. We believe this work paves the way for future developments of environmental monitoring, taking into account society requirements and how the scientific community opens to social participation.

\section{CRediT authorship contribution statement}

Cecilia Prudkin-Silva: Funding acquisition, Conceptualization, Methodology, Validation, Investigation, Writing - original draft, Writing - review \& editing, Supervision, Project administration. Esteban Lanzarotti: Funding acquisition, Conceptualization, Methodology, Validation, Investigation, Writing - original draft, Writing - review \& editing, Supervision, Project administration. Lucía Álvarez: Funding acquisition, Conceptualization, Methodology, Validation, Investigation, Project administration. María Belén Vallerga: Funding acquisition, Conceptualization, Methodology, Validation, Investigation. Matías Factorovich: Funding acquisition, Conceptualization, Methodology, Validation, Investigation. Uriel N. Morzan: Conceptualization, Methodology, Validation, Investigation, Writing - review \& editing. Margarita Petrona Gómez: Conceptualization, Validation, Investigation, Resources, Funding acquisition. Natalia Paula González: Conceptualization, Validation, Investigation, Resources, Funding acquisition. Yamila Micaela Acosta: Conceptualization, Validation, Investigation, Resources, Funding acquisition. Felicitas Carrizo: Conceptualization, Validation, Investigation, Resources, Funding acquisition. Emilio Carrizo: Conceptualization, Validation, Investigation, Resources, Funding acquisition. Silvio Galeano: Conceptualization, Validation, Investigation, Resources, Funding acquisition. María Gabriela Lagorio: Resources, Writing - review \& editing. Ángela Beatriz Juárez: Funding acquisition, Conceptualization, Resources, Writing - review \& editing. Raúl Esteban Ithuralde: Funding acquisition, Conceptualization, Methodology, Validation, Investigation, Writing original draft, Writing - review \& editing, Supervision, Project administration. Juan Manuel Romero: Funding acquisition, Conceptualization, Methodology, Software, Validation, Formal analysis, Investigation, Writing - original draft, Writing 
- review \& editing, Visualization, Supervision, Project administration. Constanza María Urdampilleta: Funding acquisition, Conceptualization, Methodology, Validation, Investigation, Writing - original draft, Writing - review \& editing, Visualization, Supervision, Project administration.

\section{Declaration of competing interest}

The authors declare that they have no known competing financial interests or personal relationships that could have appeared to influence the work reported in this paper.

\section{Acknowledgments}

Images developed by Iconoclasistas (https://iconoclasistas.net/) were used in the graphical abstract. We want to thank the MoCaSE peasant movement and all its members for their everyday willingness and wisdom and, more importantly, their tireless fight for the right to land, food sovereignty and dignified life. We especially thank the Secretary of Health of MoCaSE, and in particular to Antonia Rossell and Nicolás Bronstein, for their hard work, guidance and accompaniment. This work was supported by the Ministry of Science, Technology and Innovation 2014 "PROCODAS", Argentina grant, the Ministry of Education 2015 "Universidad, Diseño y Desarrollo Productivo", Argentina grant, the University of Buenos Aires "UBANEX", Argentina grant (2014 and 2016 editions) and School of Natural and Exact Sciences of the University of Buenos Aires "Exactas con la Sociedad", Argentina grant (fifth and sixth editions).

\section{Appendix A. Supplementary data}

Supplementary material related to this article can be found online at https://doi.org/10.1016/j.eti.2021.101479.

\section{References}

Abdel-Hamid, M.I., 1996. Development and application of a simple procedure for toxicity testing using immobilized algae. Water Sci. Technol. 33 (6), 129-138, https://doi.org/10.1016/0273-1223(96)00289-2.

Alonso, L.L., Demetrio, P.M., Agustina Etchegoyen, M., Marino, D.J., 2018. Glyphosate and atrazine in rainfall and soils in agroproductive areas of the pampas region in Argentina. Sci. Total Environ. https://doi.org/10.1016/j.scitotenv.2018.07.134.

Antonacci, A., Scognamiglio, V., 2020. BiotEchnological advances in the design of algae-based biosensors. Trends Biotechnol. 38 (3), 334-347, https://doi.org/10.1016/j.tibtech.2019.10.005.

de Baat, M.L., Bas, D.A., van Beusekom, S.A.M., Droge, S.T.J., vander Meer, F., de Vries, M., Verdonschot, P.F.M., Kraak, M.H.S., 2018. Nationwide screening of surface water toxicity to algae. Sci. Total Environ. https://doi.org/10.1016/j.scitotenv.2018.07.214.

Ben-Yoav, H., Amzel, T., Biran, A., Sternheim, M., Belkin, S., Freeman, A., Shacham-Diamand, Y., 2011. Bacterial biofilm-based water toxicity sensor. Sensors Actuators https://doi.org/10.1016/j.snb.2011.06.037.

Bischoff, H.W., Bold, H.C., 1963. Some soil algae from enchanted rock and related algae species. Phycol. Stud..

Cáceres, D.M., Gras, C., 2020. A tipping point for agricultural expansion? Technological changes and capital accumulation in Argentina's rural sector. J. Agrar. Chang. https://doi.org/10.1111/joac.12336.

Campanella, L., Favero, G., Persi, L., Tomassetti, M., 2000. New biosensor for superoxide radical used to evidence molecules of biomedical and pharmaceutical interest having radical scavenging properties. J. Pharm. Biomed. Anal. https://doi.org/10.1016/S0731-7085(00)00276-4.

Cedergreen, N., Streibig, J.C., Kudsk, P., Mathiassen, S.K., Duke, S.O., 2007. The Occurrence of Hormesis in Plants and Algae. Dose-Response, 5(2), Dose-Response.0.. https://doi.org/10.2203/dose-response.06-008.cedergreen.

Chaufan, G., Coalova, I., Del Carmen Ríos De Molina, M., 2014. Glyphosate commercial formulation causes cytotoxicity, oxidative effects, and apoptosis on human cells: Differences with its active ingredient. Int. J. Toxicol. https://doi.org/10.1177/1091581813517906.

Coalova, I., Ríos de Molina, M. del C., Chaufan, G., 2014. Influence of the spray adjuvant on the toxicity effects of a glyphosate formulation. Toxicol. In Vitro https://doi.org/10.1016/j.tiv.2014.06.014.

Corbisier, P., Van Der Lelie, D., Borremans, B., Provoost, A., De Lorenzo, V., Brown, N.L., Lloyd, J.R., Hobman, J.L., Csöregi, E., Johansson, G., Mattiasson, B., 1999. Whole cell- and protein-based biosensors for the detection of bioavailable heavy metals in environmental samples. Anal. Chim. Acta 387 (3), 235-244, https://doi.org/10.1016/S0003-2670(98)00725-9.

Duke, S.O., 1988. Glyphosate. In: Kearney, D.D. (Ed.), Herbicides: Chemistry, Degradation and Mode of Action, Marcel Dekker, New York. J. Basic Microbiol. 1-58, ISBN: 0-8247-7804-9. https://doi.org/10.1002/jobm.3620291018.

Falace, A., Tamburello, L., Guarnieri, G., Kaleb, S., Papa, L., Fraschetti, S., 2018. Effects of a glyphosate-based herbicide on fucus virsoides (fucales, ochrophyta) photosynthetic efficiency. Environ. Pollut. https://doi.org/10.1016/j.envpol.2018.08.053.

Frense, D., Müller, A., Beckmann, D., 1998. Detection of environmental pollutants using optical biosensor with immobilized algae cells. Sensors Actuators B 51 (1-3), 256-260, https://doi.org/10.1016/S0925-4005(98)00203-2.

Genty, B., Briantais, J.M., Baker, N.R., 1989. The relationship between the quantum yield of photosynthetic electron transport and quenching of chlorophyll fluorescence. Biochim. Biophys. Acta https://doi.org/10.1016/S0304-4165(89)80016-9.

Giesy, J.P., Dobson, S., Solomon, K.R., 2000. Ecotoxicological risk assessment for roundup ${ }^{\circledR}$ herbicide. Rev. Environ. Contam. Toxicol. https://doi.org/ 10.1007/978-1-4612-1156-3_2.

Gosset, A., Oestreicher, V., Perullini, M., Bilmes, S.A., Jobbágy, M., Dulhoste, S., Bayard, R., Durrieu, C., 2019. Optimization of sensors based on encapsulated algae for pesticide detection in water. Anal. Methods 11 (48), 6193-6203, https://doi.org/10.1039/c9ay02145k.

Han, S., Zhang, Q., Zhang, X., Liu, X., Lu, L., Wei, J., Li, Y., Wang, Y., Zheng, G., 2019. A digital microfluidic diluter-based microalgal motion biosensor for marine pollution monitoring. Biosens. Bioelectron. https://doi.org/10.1016/j.bios.2019.111597.

Huzlik, J., Bozek, F., Pawelczyk, A., Licbinsky, R., Naplavova, M., Pondelicek, M., 2017. Identifying risk sources of air contamination by polycyclic aromatic hydrocarbons. Chemosphere https://doi.org/10.1016/j.chemosphere.2017.04.131.

Iriel, A., Novo, J.M., Cordon, G.B., Lagorio, M.G., 2014. Atrazine and methyl viologen effects on chlorophyll-a fluorescence revisited - implications in photosystems emission and ecotoxicity assessment. Photochem. Photobiol. 90 (1), 107-112, https://doi.org/10.1111/php.12142. 
Kashem, M.A., Kimoto, K., Iribe, Y., Suzuki, M., 2019. Development of microalgae biosensor chip by incorporating microarray oxygen sensor for pesticides sensing. Biosensors https://doi.org/10.3390/bios9040133.

Lagorio, M.G., 2011. Chlorophyll fluorescence emission spectra in photosynthetic organisms. In: Chlorophyll: Structure, Production and Medicinal Uses. pp. 115-150.

Lanzarotti, E.O., Cuesta, G., Factorovich, M.H., Kucher, H., Prudkin Silva, C.R., Lichtig, P., ..., Romero, J.M., 2016. Tierra y agrotóxicos: un enfoque coproductivo en problemáticas socioambientales. Cambios y Perm. 7, 181-219.

Lupi, L., Bedmar, F., Puricelli, M., Marino, D., Aparicio, V.C., Wunderlin, D., Miglioranza, K.S.B., 2019. Glyphosate runoff and its occurrence in rainwater and subsurface soil in the nearby area of agricultural fields in Argentina. Chemosphere https://doi.org/10.1016/j.chemosphere.2019.03.090.

Magdaleno, A., Vélez, C.G., Wenzel, M.T., Tell, G., 2014. Effects of cadmium. Bull. Environ. Contam. Toxicol. https://doi.org/10.1007/s00128-013-1171-8.

Mankiewicz-Boczek, J., Nałecz-Jawecki, G., Drobniewska, A., Kaza, M., Sumorok, B., Izydorczyk, K., Zalewski, M., Sawicki, J., 2008. Application of a microbiotests battery for complete toxicity assessment of rivers. Ecotoxicol. Environ. Safety https://doi.org/10.1016/j.ecoenv.2008.02.023.

Marty, J.L., Garcia, D., Rouillon, R., 1995. Biosensors: potential in pesticide detection. TRAC Trends Anal. Chem. 14 (7), 329-333.

Mas, L.I., Aparicio, V.C., De Gerónimo, E., Costa, J.L., 2020. Pesticides in water sources used for human consumption in the semiarid region of Argentina. SN Appl. Sci. 2 (4), https://doi.org/10.1007/s42452-020-2513-x.

Masojídek, J., Souček, P., Máchová, J., Frolík, J., Klem, K., Malý, J., 2011. Detection of photosynthetic herbicides: Algal growth inhibition test vs. electrochemical photosystem II biosensor. Ecotoxicol. Environ. Safety https://doi.org/10.1016/j.ecoenv.2010.08.028.

Maxwell, K., Johnson, G.N., 2000. Chlorophyll fluorescence-a practical guide. J. Exp. Bot. 51 (345), 659-668, https://doi.org/10.1093/jexbot/51.345.659.

Moreira dos Santos, M., Moreno-Garrido, I., Gonçalves, F., Soares, A.M.V.M., Ribeiro, R., 2002. An in situ bioassay for estuarine environments using the microalga phaeodactylum tricornutum. Environ. Toxicol. Chem. https://doi.org/10.1002/etc.5620210315.

Moreira-Santos, M., Soares, A.M.V.M., Ribeiro, R., 2004. An in situ bioassay for freshwater environments with the microalga Pseudokirchneriella subcapitata. Ecotoxicol. Environ. Safety 59, 164-173. http://dx.doi.org/10.1016/j.ecoenv.2003.07.004.

Mouget, J.L., Tremblin, G., 2002. Suitability of the fluorescence monitoring system (FMS, hansatech) for measurement of photosynthetic characteristics in algae. Aquat. Bot. 74 (3), 219-231, https://doi.org/10.1016/S0304-3770(02)00104-3.

Riedel, K., 1994. Microbial sensors and their applications in environment. Exp. Tech. Phys. 40 (1), 63-76.

Ritchie, R.J., Bunthawin, S., 2010. The use of pulse amplitude modulation (PAM) fluorometry to measure photosynthesis in a CAM orchid, dendrobium spp. (d. cV. Viravuth pink). Int. J. Plant Sci. https://doi.org/10.1086/653131.

Roggo, C., van der Meer, J.R., 2017. Miniaturized and integrated whole cell living bacterial sensors in field applicable autonomous devices. In: Current Opinion in Biotechnology. https://doi.org/10.1016/j.copbio.2016.11.023.

Saaty, T.L., 1990. How to make a decision: The analytic hierarchy process. European J. Oper. Res. https://doi.org/10.1016/0377-2217(90)90057-I.

Saleh, I.A., Zouari, N., Al-Ghouti, M.A., 2020. Removal of pesticides from water and wastewater: Chemical, physical and biological treatment approaches.. Environ. Technol. Innov. 19, 101026, https://doi.org/10.1016/j.eti.2020.101026.

Salman, J.M., Abdul-Adel, E., Alkaim, A.F., 2016. Effect of pesticide glyphosate on some biochemical features in cyanophyta algae oscillatoria limnetica. Int. J. PharmTech Res..

Sassolas, A., Prieto-Simón, B., Marty, J.-L., 2012. Biosensors for pesticide detection: New trends. Am. J. Anal. Chem. 03 (03), 210-232, https: //doi.org/10.4236/ajac.2012.33030.

Shao, C.Y., Howe, C.J., Porter, A.J.R., Glover, L.A., 2002. Novel cyanobacterial biosensor for detection of herbicides. Appl. Environ. Microbiol. 68 (10), 5026-5033, https://doi.org/10.1128/AEM.68.10.5026-5033.2002.

Smedbol, É, Gomes, M.P., Paquet, S., Labrecque, M., Lepage, L., Lucotte, M., Juneau, 2018. Effects of low concentrations of glyphosate-based herbicide factor $540^{\circledR}$ on an agricultural stream freshwater phytoplankton community. Chemosphere https://doi.org/10.1016/j.chemosphere.2017.10.128.

Peña Vázquez, E., Maneiro, E., Pérez-Conde, C., Moreno-Bondi, M.C., Costas, E., 2009. Microalgae fiber optic biosensors for herbicide monitoring using sol-gel technology. Biosens. Bioelectron. https://doi.org/10.1016/j.bios.2009.05.013.

Védrine, C., Fabiano, S., Tran-Minh, C., 2003. Amperometric tyrosinase based biosensor using an electrogenerated polythiophene film as an entrapment support. Talanta https://doi.org/10.1016/S0039-9140(02)00540-4.

Vera, M.S., Juárez, Á.B., Pizarro, H.N., 2014. Comparative effects of technical-grade and a commercial formulation of glyphosate on the pigment content of periphytic algae. Bull. Environ. Contam. Toxicol. https://doi.org/10.1007/s00128-014-1355-X.

Zhang, X., Qin, B., Deng, J., Wells, M., 2017. Whole-cell bioreporters and risk assessment of environmental pollution: A proof-of-concept study using lead. Environ. Pollut. 229, 902-910, https://doi.org/10.1016/j.envpol.2017.07.068.

Zhang, Q., Song, Y., Amor, K., Huang, W.E., Porcelli, D., Thompson, I., 2019. Monitoring cr toxicity and remediation processes - combining a whole-cell bioreporter and cr isotope techniques. Water Res. https://doi.org/10.1016/j.watres.2019.01.009. 